\title{
DETERMINATION OF VOLATILE BIOACTIVE COMPOUNDS FROM EXTRACTS OF BAEL (AEGLE MARMELOS) PLANT PARTS AND THEIR COMPARATIVE ANALYSIS
}

\author{
NIDHI SHARMA, WIDHI DUBEY* \\ School of Sciences, JECRC University, Jaipur - 302 017, Rajasthan, India. Email: widhi.dubey@yahoo.co.in
}

Received: 08 November 2017, Revised and Accepted: 20 December 2017

\begin{abstract}
Objective: The main objective of this study is to determine the bioactive compounds from the extracts of wildly growing Aegle marmelos plant parts.

Methods: A. marmelos root, stem, leaves, bark, fruit peel, and pulp were screened for the presence/absence of phytochemicals. Bioactive compounds in all the plant parts were analyzed by gas chromatography-mass spectrometry (GC/MS) analysis. For evaluation of bioactive compounds first, the column chromatography was done using various solvents and found that the methanolic extracts gave better elution and separation of compounds and hence used further for GC/MS analysis.

Result: GC/MS analysis revealed chromatograms of methanol extract of $A$. marmelos plant parts, and all the plant parts were found to have a number of phytochemicals. Some compounds, namely, benzene, nitro-, benzenepropanoic acid, 3, 5-bis (1, 1-dimethylethyl)-4-hydroxy-, methyl ester, and tetradecene were found in all parts with a varying percentage. Phenol only found in the fruit of the plant with more percentage in fruit peel (4.38\%) than in fruit pulp (0.58\%). Dibutyl phthalate is the major compound found in Aegle root (10.43\%), fruit peel (34.56\%), and pulp (13.18\%). Other important compounds such as coumarin (2H-1-Benzopyran-2-one, 7-[(3,7-dimethyl-2,6-octadienyl)oxy]-, (E)-), skimmianine (Furo[2,3-b] quinoline, 4,7,8-trimethoxy-), and cyclobarbital were found in plant root.
\end{abstract}

Conclusion: After the GC/MS analysis, it was concluded that all the parts of this wildly growing plant contain a significant amount of pharmaceutically important compounds.

Keywords: Aegle marmelos, Rutaceae, Gas chromatography-mass spectrometry analysis, Bioactive compounds, Biomedicine.

(C) 2018 The Authors. Published by Innovare Academic Sciences Pvt Ltd. This is an open access article under the CC BY license (http://creativecommons. org/licenses/by/4. 0/) DOI: http://dx.doi.org/10.22159/ajpcr.2018.v11i3.23529

\section{INTRODUCTION}

Plants synthesize a variety of secondary metabolites against the infectious agents [1]. Bioactive compounds are defined as secondary metabolites that elicit pharmacological or toxicological effects in man and animals. Frequent use of synthetic drugs has made the pathogens resistant to multiple drugs. This impels the need to screen medicinal plants for novel bioactive compounds due to their biodegradability, safety, and fewer side effects [2].

Aegle marmelos is one such medicinal plant having a plethora of bioactive compounds in every plant part. Mentions of this plant have also been found in the pre-historic writings dating back to 800 B.C. It was not only known in the ancient era for its medicinal properties but also being studied nowadays extensively using advanced scientific techniques. A. marmelos, plant of family Rutaceae, is commonly known as wood apple plant and other vernacular names are Bael Fruit, Indian Bael, Holy Fruit, Golden Apple, Elephant Apple, Indian Quince, and Stone Apple [3]. It subsists well in a wide range of climatic conditions and can be cultivated worldwide. It is a subtropical plant which can grow up to an altitude of $1200 \mathrm{~m}$ from the sea level and also in the dry forests of hilly and plain areas. It is native to India and grown throughout India, mainly near the temples due to its mythological importance [4]. It has its origin from the Eastern Ghats and Central India. It has been used in medicines due to its significant phytochemical constitution making it potent as a remedy for diseases such as diabetes, peptic ulcer, inflammation, diarrhea and dysentery, constipation, respiratory infection, and cancer. It also has cardioprotective, antimicrobial, radioprotective, antipyretic, analgesic, antioxidant, hepatoprotective, and wound healing properties [5].
Various other researchers throughout the world have done the gas chromatography/mass spectrometry (GC/MS) analysis of A. marmelos plant parts, but till now no researcher has reported GC/MS analysis of the $A$. marmelos fruit peel. In this study, GC/MS analysis of fruit peel shows that it possesses a significant amount of the bioactive compounds which are potent as antioxidants. Wildly growing $A$. marmelos plant from the semiarid area of the Indian state of Rajasthan was studied for its bioactive compound composition through GC/MS analysis. Bioactive compounds from different plant parts such as root, stem, leaf, bark, fruit peel, and pulp were compared and analyzed.

\section{METHODS}

\section{Plant material and extraction}

Bilva plant samples were collected from fields of Chaumun area of Jaipur district in Rajasthan. Identification of the plant was confirmed by Rajasthan Agricultural Research Institute, Jaipur. A. marmelos plant parts, leaves, root, stem, bark, fruit peel, and pulp were taken and shade dried and then crushed to make a fine powder. For evaluation of bioactive compounds first, the column chromatography was done using various solvents and it was found that the methanolic extracts gave better elution and separation of compounds and hence used further for GC/MS analysis.

\section{GC/MS}

GC/MS technique is used in this study to identify the bioactive components present in the extract. This method involves a very little amount of the test sample and gives the molecular weights of even fraction of compounds. GC/MS analysis of this extract can be performed using GC SHIMADZU QP2010 system and GC interfaced to a MS (GC/MS) equipped with Elite-1 fused silica capillary column (Length: $30.0 \mathrm{~m}$, Diameter: $0.25 \mathrm{~mm}$, film thickness: $0.25 \mu \mathrm{m}$, Composed 
of $100 \%$ dimethyl polysiloxane). The components can be identified by comparing their retention times with those of authentic samples as well as by comparing their mass spectra with those of Wiley 275 library [6].

\section{RESULT}

The bioactive fraction on GC/MS analysis revealed chromatograms of methanol extract of $A$. marmelos plant parts. Some compounds, namely, benzene, nitro-, benzenepropanoic acid, 3,5-bis(1,1-dimethylethyl)-4hydroxy-, methyl ester, and tetradecene were found in all the plant parts with a varying percentage. Phenol only found in the fruit of the plant with more percentage in fruit peel $(4.38 \%)$ than in fruit pulp $(0.58 \%)$. Phenol is supposed to be responsible for the antioxidant activity of the sample. Dibutyl phthalate is the major compound found in Aegle root (10.43\%), fruit peel (34.56\%), and pulp (13.18\%), having the highest

Table 1: Compounds identified in the Aegle marmelos fruit peel

\begin{tabular}{lllll}
\hline Peak no. $^{\mathbf{a}}$ & Retention time $^{\mathbf{b}}$ & Area $^{\mathbf{c}}$ & Area\%d $^{\mathbf{d}}$ & Name $^{-}$ \\
\hline 1 & 5.319 & 28558 & 4.38 & Phenol \\
2 & 6.698 & 47781 & 7.33 & Benzene, Nitro- \\
4 & 9.722 & 31092 & 4.77 & 5-Tetradecene, (E)- \\
5 & 11.426 & 49454 & 7.59 & 5-Tetradecene, (E)- \\
6 & 12.949 & 45627 & 7.00 & 5-Eicosene, (E)- \\
7 & 13.455 & 225194 & 34.56 & Dibutyl phthalate \\
8 & 13.940 & 120586 & 18.50 & Benzenepropanoic acid, 3,5-bis (1,1-dimethylethyl)-4-hydroxy-, methyl ester \\
9 & 14.326 & 34662 & 5.32 & 5-Eicosene, (E)- \\
10 & 15.581 & 25527 & 3.92 & Phosphonic acid, dioctadecyl ester \\
& & 651663 & 100.00 & \\
\hline
\end{tabular}

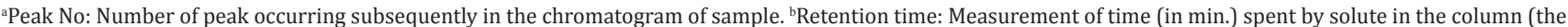
time from injection into the column is made to when elution occurs). 'Area: Area covered by a peak in chromatogram which is proportional to the amount of compound present. ${ }^{\mathrm{d}}$ Area \%: It is calculated by dividing the area of each peak by total area and multiply it by 100

Area $\%=$ Area of Peak $\div$ Total Area $\times 100$

Table 2: Compounds identified in the Aegle marmelos root

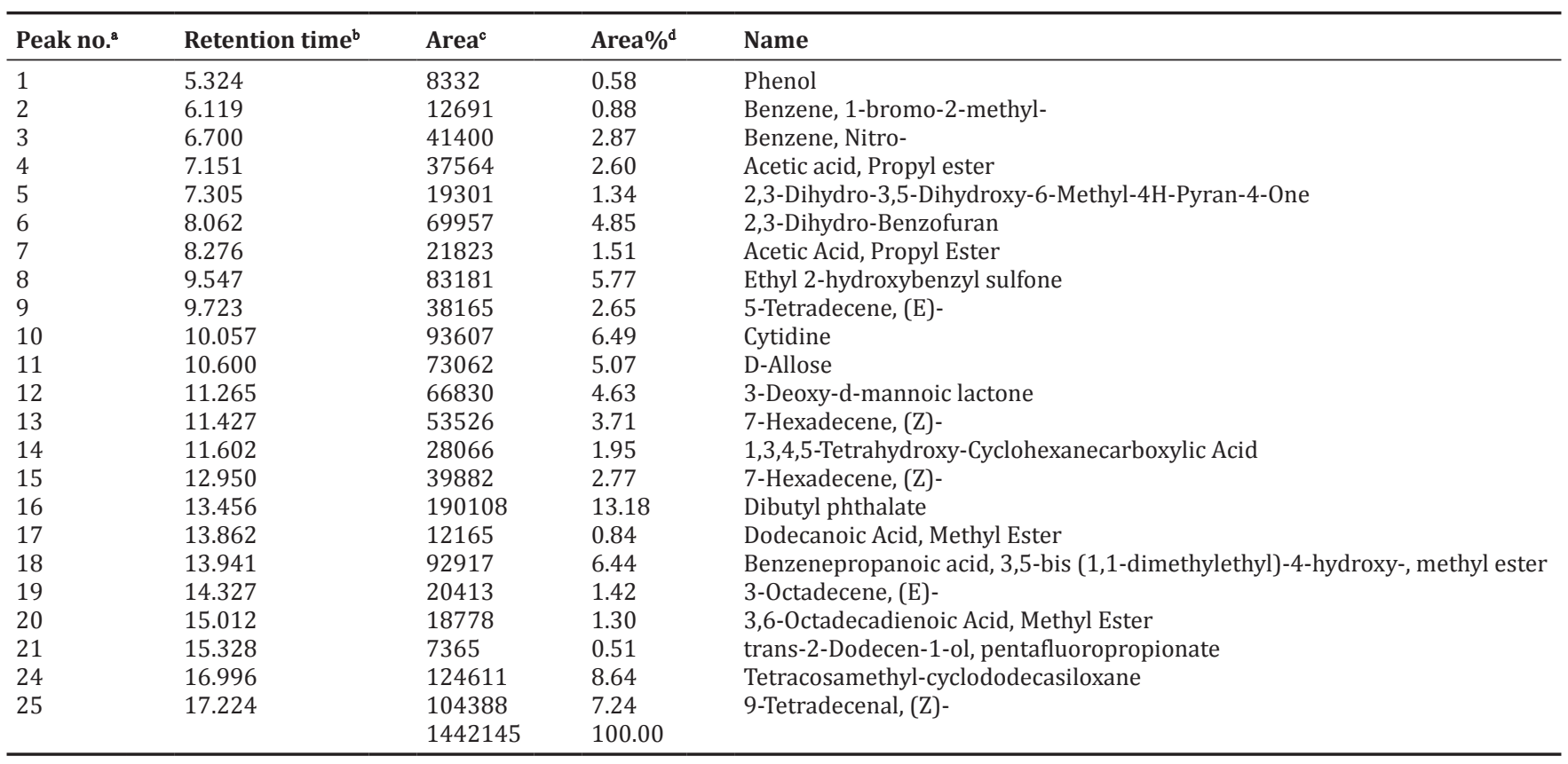

Table 3: Compounds identified in the Aegle marmelos stem

\begin{tabular}{lllll}
\hline Peak no. $^{\mathbf{a}}$ & Retention time $^{\mathbf{b}}$ & Area $^{\mathbf{c}}$ & Area\% $^{\mathbf{d}}$ & Name \\
\hline 1 & 6.122 & 10638 & 1.57 & Benzene, 1-bromo-2-methyl- \\
2 & 6.703 & 39789 & 5.87 & Benzene, nitro- \\
3 & 7.820 & 28507 & 4.21 & 1-Propene, 3-(ethenyloxy)- \\
5 & 9.723 & 44302 & 6.54 & 5-Tetradecene, (E)- \\
6 & 11.427 & 50107 & 7.40 & 5-Tetradecene, (E)- \\
7 & 12.344 & 16941 & 2.50 & Hexestrol, 0-trifluoroacetyl- \\
8 & 12.410 & 17360 & 2.56 & Spiro-1-(cyclohex-2-ene)-2'-(5'-oxabicyclo[2.1.0]pentane), 1',4',2,6,6-pentamethyl- \\
9 & 12.700 & 13987 & 2.06 & Hexestrol \\
10 & 12.951 & 44074 & 6.50 & 9-Octadecene, (E)- \\
11 & 13.456 & 217627 & 32.12 & 1,2-Benzenedicarboxylic acid, butyl 2-methylpropyl ester \\
12 & 13.942 & 116224 & 17.15 & Benzenepropanoic acid, 3,5-bis (1,1-dimethylethyl)-4-hydroxy-, methyl ester \\
13 & 14.328 & 33689 & 4.97 & 9-Eicosene, (E)- \\
14 & 15.584 & 27374 & 4.04 & Z-5-Nonadecene \\
& & 677574 & 100.00 & \\
\hline
\end{tabular}


amount in the fruit peel. Whereas, some other important compounds such as coumarins (2H-1-benzopyran-2-one, 7-[(3,7-dimethyl2,6-octadienyl)oxy]-, (E)-), skimmianine (Furo[2,3-b] quinoline, 4,7,8-trimethoxy-), and cyclobarbital were found in plant root only. Hence, after a comparative analysis of compounds identified, it was found that there are compounds which are found only in particular plant parts (Tables 1-7)

\section{DISCUSSION}

Jorge et al. from Cuba in 2005 did the GC/MS analysis of A. marmelos leaf and identified 65 compounds comprising more than $85 \%$ leaf oil. Major components identified were $\beta$-caryophyllene $(10.0 \%)$ and $\delta$-cadinene $(12.1 \%$ ) [7]. Satyal et al. from Nepal in 2012 also identified
82 compounds by GC/MS analysis of Aegle leaves [8]. In 2014, Mujeeb et al. from Lucknow and Rajeshkannan and Lakshmanan from Tamil Nadu also studied the A. marmelos leaves and fruit, respectively, and identified various compounds by GC/MS analysis [9,10]. Bajaniya et al. in 2015 studied the fatty acid profile of Aegle seed oils and characterized the phytochemicals present in it through GC/MS analysis [11]. Nadhiya and Vadivazhagi in 2015 studied the A. marmelos and Mentha piperita leaves. In this study, GC/MS were used to identify phytochemicals present in the A. marmelos with M. piperita leaves extract. Phytochemical identified from A. marmelos and M. piperita combined extract was used to investigate the various antioxidant activities [12]. In 2016, Ritu Jha and Rajinder Gupta developed energy drink from the combination of A. marmelos, Rubia cordifolia, Phyllanthus emblica, and Beta vulgaris

Table 4: Compounds identified in the Aegle marmelos leaves

\begin{tabular}{lllll}
\hline Peak no. $^{\mathbf{a}}$ & Retention time $^{\mathbf{b}}$ & Area $^{\mathbf{c}}$ & Area\% $^{\mathbf{d}}$ & Name \\
\hline 1 & 6.006 & 18779 & 2.18 & Cyclobutane, 1,2-bis (1-methylethenyl)-, trans- \\
2 & 6.700 & 35919 & 4.18 & Benzene, nitro- \\
3 & 9.723 & 35955 & 4.18 & 4-Tetradecene, (E)- \\
4 & 10.573 & 14078 & 1.64 & Benzene, 1-methyl-4-(1,2,2-trimethylcyclopentyl)-, (R)- \\
5 & 11.425 & 51774 & 6.02 & 7-Tetradecene, (E)- \\
6 & 12.949 & 45396 & 5.28 & 7-Hexadecene, (Z)- \\
7 & 13.262 & 13497 & 1.57 & 3-Tridecene \\
8 & 13.454 & 295847 & 34.40 & 1,2-Benzenedicarboxylic acid, butyl 2-methylpropyl ester \\
9 & 13.940 & 106510 & 12.38 & Benzenepropanoic acid, 3,5-bis (1,1-dimethylethyl)-4-hydroxy-, methyl ester \\
10 & 14.325 & 28226 & 3.28 & 9-Eicosene, (E)- \\
11 & 14.922 & 54060 & 6.29 & Dimethyl [bis[(4,8,8-trimethyldecahydro-1,4-methanoazulen-9-yl) methoxy]\}silane \\
12 & 15.582 & 30770 & 3.58 & 1,7-Dimethyl-4-(1-methylethyl) cyclodecane \\
13 & 18.206 & 83193 & 9.67 & Carbamic acid, methylnitroso-, 1-naphthalenyl \\
& & 860116 & 100 & \\
\hline
\end{tabular}

Table 5: Compounds identified in the Aegle marmelos bark

\begin{tabular}{lllll}
\hline Peak no. $^{\mathbf{a}}$ & Retention time $^{\mathbf{b}}$ & Area $^{\mathbf{c}}$ & Area\% $^{\mathbf{d}}$ & Name \\
\hline 1 & 6.701 & 33134 & 4.26 & Benzene, nitro- \\
2 & 9.724 & 26666 & 3.43 & 6-Dodecene, (E)- \\
3 & 11.214 & 15171 & 1.95 & 2,5-Dihydroxy-4-isopropyl-2,4,6-cycloheptatrien-1-one \\
4 & 11.425 & 47739 & 6.13 & 7-Tetradecene, (E)- \\
5 & 12.697 & 13118 & 1.69 & Hexestrol, 0-trifluoroacetyl- \\
6 & 12.949 & 48494 & 6.23 & 5-Octadecene, (E)- \\
7 & 13.456 & 205078 & 26.35 & 1,2-Benzenedicarboxylic acid, butyl 2-methylpropyl ester \\
8 & 13.941 & 96234 & 12.36 & Benzenepropanoic acid, 3,5-bis (1,1-dimethylethyl)-4-hydroxy-, methyl ester \\
9 & 14.094 & 28914 & 3.71 & Isoquinolin-6-ol, 7-methoxy-1-methyl- \\
10 & 14.326 & 32293 & 4.15 & 1-Hexadecanol \\
11 & 16.485 & 197906 & 25.42 & 2-(1-Hydroxy-1-methylethyl)-2,3-dihydrofuro[3,2-g] chromen-7-one \\
12 & 16.733 & 33654 & 4.32 & (S)-7-Hydroxy-8,8-dimethyl-7,8-dihydropyrano (3,2-g) chromen-2 (6H)-one \\
\end{tabular}

Table 6: Compounds identified in the Aegle marmelos fruit pulp

\begin{tabular}{lllll}
\hline Peak no. $^{\mathbf{a}}$ & Retention time $^{\mathbf{b}}$ & Area $^{\mathbf{c}}$ & Area\% $^{\mathbf{d}}$ & Name \\
\hline 1 & 6.121 & 12707 & 0.63 & Benzene, 1-bromo-2-methyl- \\
2 & 6.701 & 41879 & 2.08 & Benzene, nitro- \\
4 & 7.782 & 39209 & 1.95 & 7-Tetradecene, (Z)- \\
5 & 7.898 & 95566 & 4.75 & Tricyclo[3.3.1.1 (3,7)]decan-6-one, 2-(4-allyloxyphenyl)-5,7-dipropyl-1,3-diaza- \\
6 & 9.723 & 30074 & 1.49 & 7-Tetradecene, (E)- \\
7 & 11.428 & 52424 & 2.60 & 5-Tetradecene, (E)- \\
8 & 12.950 & 41437 & 2.06 & 5-Octadecene, (E)- \\
9 & 13.456 & 209997 & 10.43 & Dibutyl phthalate \\
10 & 13.941 & 111967 & 5.56 & Benzenepropanoic acid, 3,5-bis (1,1-dimethylethyl)-4-hydroxy-, methyl ester \\
11 & 14.326 & 41176 & 2.05 & 5-Eicosene, (E)- \\
12 & 15.581 & 24992 & 1.24 & n-Heptadecanol-1 \\
13 & 16.665 & 117565 & 5.84 & Furo[2,3-b] quinoline, 4,7,8-trimethoxy- \\
15 & 18.387 & 73670 & 3.66 & 2H-1-Benzopyran-2-one, 7-[(3,7-dimethyl-2,6-octadienyl) oxy]-, (E)- \\
17 & 19.083 & 40266 & 2.00 & Cyclobarbital \\
18 & 19.508 & 889357 & 44.19 & 2,6-Dimethyl-3,5,7-octatriene-2-ol, E, E- \\
& & 2012616 & 100.00 & \\
\hline
\end{tabular}


Table 7: Some important compounds identified

\begin{tabular}{|c|c|c|}
\hline Compound & Description [16] & Plant part \\
\hline Dibutyl phthalate (DBP) & $\begin{array}{l}\text { Additive to adhesives, printing inks and makes } \\
\text { nail polish flexible. It acts as ectoparasiticide and } \\
\text { also as a plasticizer }\end{array}$ & $\begin{array}{l}\text { Found in root, fruit } \\
\text { peel, and pulp }\end{array}$ \\
\hline n-Heptadecanol-1- & $\begin{array}{l}\text { A chemical compound from the group of fatty } \\
\text { alcohols used as an antifoaming agent and in the } \\
\text { synthesis of complex organic compounds }\end{array}$ & Found in the root \\
\hline Cyclobarbital (cyclobarbitone) & $\begin{array}{l}\text { It is a barbiturate derivative drug which is used to } \\
\text { treat insomnia in Russia }\end{array}$ & Found in the root \\
\hline $\begin{array}{l}\text { Coumarin (2H-1-Benzopyran-2-one, } \\
\text { 7-[(3,7-dimethyl-2,6-octadienyl) oxy]-, (E)-) }\end{array}$ & $\begin{array}{l}\text { It is a fragrant compound in the benzopyrone } \\
\text { chemical class and used in perfumes and fabric } \\
\text { conditioners, aroma enhancer in pipe tobaccos } \\
\text { and alcoholic drinks. It is also used as a precursor } \\
\text { in the synthesis of anticoagulant. It is banned as a } \\
\text { flavoring food additive, due to its hepatotoxicity. } \\
\text { "Coumarins" are a type of Vitamin K antagonists }\end{array}$ & Found in the root \\
\hline Isoquinolin-6-ol, 7-methoxy-1-methyl- & $\begin{array}{l}\text { It is a quinoline alkaloid with painkilling } \\
\text { properties }\end{array}$ & Found in the bark \\
\hline 5-Octadecene, (E)- & $\begin{array}{l}\text { An alkene with the molecular formula } \mathrm{C} 18 \mathrm{H} 36 \\
\text { and used in the synthesis of colloidal quantum } \\
\text { dots. It acts as an antimicrobial agent }\end{array}$ & $\begin{array}{l}\text { Root, stem, bark, and } \\
\text { fruit pulp }\end{array}$ \\
\hline Hexestrol, O-trifluoroacetyl- & $\begin{array}{l}\text { It is also known as hexanestrol, hexoestrol, } \\
\text { and dihydrodiethylstilbestrol. It was used to } \\
\text { treat estrogen deficiency but is now no longer } \\
\text { employed medically }\end{array}$ & Found in the stem \\
\hline $\begin{array}{l}\text { Marmesin (2-(1-Hydroxy-1-methylethyl)-2,3-dihydrofuro[3,2-g] } \\
\text { chromen-7-one) }\end{array}$ & $\begin{array}{l}\text { It is a compound precursor in psoralen and linear } \\
\text { furanocoumarins biosynthesis }\end{array}$ & Found in the bark \\
\hline Skimmianine (Furo[2,3-b] quinoline, 4,7,8-trimethoxy) & $\begin{array}{l}\text { This group of alkaloids is essentially limited } \\
\text { to plant family Rutaceae. Simplest member is } \\
\text { dictamnine, whereas skimmianine is the most } \\
\text { widespread. It has in vitro pharmacological } \\
\text { properties such as antimicrobial, antiviral, } \\
\text { mutagenic, and cytotoxic }\end{array}$ & Found in the root \\
\hline
\end{tabular}

and its phytochemical, nutritive, and antimicrobial analysis. GC/MS screening of sample revealed the presence of hexadecanoic acid and octadecanoic acid. The ingredients used in the energy drink had very good nutrition as well as pharmacological use [13]. Kasireddy et al. studied the neuroprotective potential and efficacy of $A$. marmelos fruit extract against neurodegenerative disorders, and it was concluded that dry fruit extract improves antihypoxic effects induced by sodium nitrite. This effect was supposed to be mediated by the antioxidant properties caused by the bioactive compounds present in the plant [14]. Antibacterial activity of $A$. marmelos (L.) Correa was studied by Yadav et al., and it was found that methanolic extracts of the plant showed better inhibition activity which may be due to the efficiency of methanol to extract more bioactive compounds than other solvents [15].

After reviewing the research work on A. marmelos plant parts from different countries and comparing it with the present study, it was observed that compounds identified also varied with the geographical and climatic conditions.

\section{CONCLUSION}

In this study, the plant parts were found to have a significant amount of bioactive compounds responsible for its medicinal and phytochemical importance. This study has been done on the wild variety of $A$. marmelos plant grown in Rajasthan state of India, which is a semiarid area. Rajasthan state covers almost 60\% area of the Thar Desert of India. This plant can be seen almost everywhere and mostly near the temples due to its mythological importance. Charak, the "father of medicine" from ancient Indian history, also mentioned the importance of $A$. marmelos in medicine in his treatise. As this plant can thrive well in a wide range of climatic conditions, it would be of dire importance to grow this plant in the desert area of Rajasthan under afforestation program for reducing the growth of desert as well as serving as a potential source of medicine. The results of this GC/MS analysis show that various parts of the plant contain sufficient amount of plethora of bioactive compounds which play a major role in providing the plant its medicinal property.

\section{ACKNOWLEDGMENT}

We thank JECRC University, Jaipur, and Ayushraj Enterprises Pvt. Ltd., Jaipur, for providing the laboratory facility to do the research work. We also acknowledge the help from farmers of Chaumun Agricultural Farms, Jaipur, Rajasthan.

\section{AUTHORS CONTRIBUTION}

NS reviewed the literature of same nature research work, carried out the experiments and prepared the manuscript. WD helped to carry out Study, manuscript preparation and critical revision of the manuscript. Both the authors agree with the content of the manuscript.

\section{CONFLICT OF INTEREST}

There is no conflict of interests.

\section{REFERENCES}

1. Piasecka A, Jedrzejczak-Rey N, Bednarek P. Secondary metabolites in plant innate immunity: Conserved function of divergent chemicals. New Phytol 2015;206:948-64.

2. Bernhoft A. Bioactive Compounds in Plants-Benefits and Risks for Man and Animals. The Norwegian Academy of Science and Letters. Oslo: Proceedings from a Symposium Held at The Norwegian Academy of Science and Letters; 2008.

3. Lim TK. Aegle marmelos. Edible Medicinal and Non-Medicinal Plants: 
Fruits. $4^{\text {th }}$ ed. London: Springer; 2012. p. 594-615.

4. Lmbole VB, Murti K, Kumar U, Bhatt SP, Gajera V. Phytopharmacological properties of Aegle marmelos as a potential medicinal tree: An Overview. Int J Pharm Sci Rev Res 2010;5:67-72.

5. Upadhyay RK. Bel plant: A source of pharmaceuticals and ethno medicines. Int J Green Pharm 2015;9:205-22.

6. Uma Devi KJ, Vanitha V, Vijayalakshmi K, Tilton F. Determination of bioactive components of Aegle marmelos L. leaves by GC-MS analysis. Indian Streams Res J 2011;1:1-4.

7. Jorge AP, Rolando M, Victor F. Volatile compounds from leaves of Aegle marmelos (L.) Correa grown in Cuba. Rev CENIC Cien Químicas 2005;36:71-3

8. Satyal P, Woods KE, Dosoky NS, Neupane S, Setzer WN. Biological activities and volatile constituents of Aegle marmelos (L.) Correa from Nepal. J Med Active Plants 2012;1:114-22.

9. Mujeeb F, Bajpai P, Pathak N. Phytochemical evaluation, antimicrobial activity and determination of bioactive compounds from leaves of Aegle marmelos. Biomed Res Int 2014;2014:14.

10. Rajeshkannan C, Lakshmanan G. Quantification of chlorogenic acid from aqueous and methanolic extracts of wood apple (Aegle marmelos C. Linn) by GC-MS Ion-trap. Int J Innov Res Sci Eng Technol 2014;3:11087-93.

11. Bajaniya VK, Kandoliya UK, Bodar NH, Bhadja NV, Golakiya BA. Fatty acid profile and phytochemical characterization of Bael seed (Aegle marmelos L.) oil. Int J Curr Microbiol Appl Sci 2015;4:97-102.

12. Nadhiya $H$, Vadivazhagi KM. Antioxidant and phytochemical properties of combination of leaves of Aegle marmelos and Mentha piperita. Int Res J Pharm Biosci 2015;2:1-9.

13. Jha R, Gupta RK. Development of energy drink containing Aegle marmelos, Rubia cordifolia, Phyllanthus emblica and Beta vulgaris and its phytochemical, nutritive and antimicrobial analysis. J Pharm Phytochem 2016;5:186-93.

14. Kasireddy P, Khumanthem DS, Prashanti P, Manguluri P. Neuroprotective potential and efficacy of neurodegenerative disorders of fruit extract of Aegle marmelos. Int J Pharm Pharm Sci 2015;7:1-5.

15. Yadav SS, Dahiya K, Showkat AG, Gulia SK. Antibacterial activity of Aegle marmelos (L) Correa. Int J Pharm Pharm Sci 2015;7:1-3.

16. Available from: https://www.pubchem.ncbi.nlm.nih.gov. 